\title{
Development of Social Infrastructure in the Russian Regions
}

\author{
EREMEEVA E.A. ${ }^{1}$, VOLKOVA N.V. ${ }^{2}$, KHALILOVA T.V. ${ }^{3}$ \\ ${ }^{I}$ Kazan Federal University, Institute of Management, Economics and Finance, Kazan, (RUSSIA) \\ ${ }^{2}$ Kazan Federal University, Institute of Management, Economics and Finance, Kazan, (RUSSIA) \\ ${ }^{3}$ Kazan Federal University, Institute of Management, Economics and Finance, Kazan, (RUSSIA)
}

\begin{abstract}
The paper describes the study of the social infrastructure state in some Russian regions.

Currently, social infrastructure is considered as a factor in the development of society and the economy of a territory. It is focused, on the one hand, on meeting the needs of an individual in education, maintaining health, comfortable living, and on the other, on solving socially significant problems related to the development of human capital, modernization of production, increasing labor productivity, attracting investment in the region's economy and etc. In this regard, the study of a territory infrastructure by the example of Russian regions seems relevant at the moment. Through the use of a group of methods (integral evaluation, ranking, classification, etc.) an assessment was carried out and analysis of social infrastructure and its individual sectors (preschool, school, and vocational training; health, science, housing and communal services) in some regions of Russia was performed. According to the results of the study, three groups of regions were identified with high, satisfactory and low levels of social infrastructure development. For each group of regions, tools were proposed that could improve the state of social infrastructure for the benefit of the population, including public-private partnerships in implementing infrastructure projects.
\end{abstract}

Keywords: social infrastructure, region, education, healthcare, science, housing and communal services, a public-private partnership

JEL: I10

UDK: 005.35:332.1(470)

332.142:314.1

\section{Introduction}

In the modern world, the main engine of progress is a man with his knowledge and abilities. In this regard, currently the most relevant is the formation for him of most comfortable conditions in which he would be able to develop himself and improve the world around him. The main place in such conditions is occupied by social infrastructure. It is focused, on the one hand, on meeting the needs of an individual in education, maintaining health, comfortable living, and on the other, on solving socially significant problems related to the development of human capital, increasing labour productivity, attracting investments, etc. This proves the relevance and practical significance of the study of social infrastructure development.

If we turn to the situation in Russia, it can be noted that the level of development of regions in the Russian Federation differs considerably from each other. This gives rise to serious regional differentiation in social infrastructure, which affects the development of the entire state. In this regard, it seems appropriate to consider the experience of the development of social 
objects at the regional level. Such a study will allow us to compare the experience of different regions, as well as offer practical recommendations for their elimination.

The relevance of the chosen topic proves the interest of other authors in it. The issues of the influence of social infrastructure on the life of the population and the use of various mechanisms for its development are more and more often considered in scientific papers. So, Y. Cui and Y. Sun conduct a study of the impact of social infrastructure on the development of the territory and society. As part of their work, the authors study three aspects of the impact: on the economy, on the health of citizens, and the development of the territory [1]. P. Braveman and L. Gottlieb consider the impact of socio-economic conditions, which include social infrastructure, on human health and their life expectancy [2]. L.J. Kolbe also considers the impact of social conditions on health but pays attention not to society as a whole, but only to schoolchildren [3]. It should be noted that while traditionally the main attention was paid to such fundamental branches of social infrastructure like education and healthcare, now some authors are focusing on newer infrastructure and electronic technologies that increase the population's access to necessary goods $[4,5]$. The importance of social infrastructure is also recognized by politicians. For example, this is evidenced by China's policy, where a rural infrastructure development program has been adopted for rural development. Zou, H., Luan, F., Xi, H., Yang, B. write about this in their scientific work [6].

As for the mechanisms of social infrastructure development, the most interesting for study are the mechanisms of attracting private capital in this area, including public-private partnerships, social entrepreneurship, and attracting foreign investment in infrastructure projects $[7,8,9,10]$.

Two indicated aspects are also mentioned within the framework of this paper. The analysis of the most important sectors of the social infrastructure for the population, which determine the level, quality, and comfort of the life of the population in the Russian regions, was carried out. The issue of using various mechanisms for attracting private capital to infrastructure projects in the regions of the Russian Federation is also raised.

\section{Methodology}

The analysis of the social infrastructure development in several regions of Russia was carried out based on a group of methods: the mathematical method, integral assessment and ranking according to its results, and also classification. The study was carried out in several stages.

At the first stage, statistics were collected on the development of the social sphere in some regions. More than 20 indicators were distinguished and divided into 5 thematic blocks:

- Pre-school and school education (the number of kindergartens, the number of children in them, utilized capacity of schools, etc.),

- Vocational education (the number of secondary and higher professional educational organizations and the number of their pupils);

- Science (the number of scientific organizations, the amount of investment in scientific development, etc.),

- Healthcare (the number of hospitals, the number of doctors in them, their workload, etc.),

- Housing and communal services (housing conditions, cost of utilities, etc.).

Further, information on these indicators was reduced to a single normalized form based on the following mathematical calculations:

$$
\mathrm{R}=(\mathrm{Xi}-\mathrm{X} \min ) /(\mathrm{Xmax}-\mathrm{Xmin})
$$

if the highest value of the indicator is better, or

$$
\mathrm{R}=(\mathrm{Xmax}-\mathrm{Xi}) /(\mathrm{Xmax}-\mathrm{Xmin}) \text {, }
$$


if the minimum value is better. Here, $\mathrm{Xi}$ is the value of the indicator in the region in the specified year, Xmin and Xmax are the minimum and maximum values of the indicator among the estimated regions. As a result of linear scaling, all calculated values fell in the interval [0; 1]. Such calculations made it possible to carry out an integral assessment of regions in the future due to summarizing normalized indicators.

The regions were ranked on the basis of a total assessment calculated as the sum of the estimates for all the thematic blocks. In turn, the estimate for each of the blocks was calculated as the arithmetic average estimate.

The regions were ranked from 1 - the best assessment of the development of the social sphere, 14 - the worst. According to the ranking results of the regions, as well as based on a comparison of the estimates of the blocks and regions, the regions of the Russian Federation were classified according to the level of their social infrastructure development.

\section{Results}

Based on the statistical data for 2018, regional estimates for each thematic block and a general integrated assessment of the regions were calculated according to the selected indicators and blocks of the social sphere [11]. According to the results of calculations, a rating position was assigned to each region. The indicated information is shown in table 1.

Table 1. The results of the assessment of the development of the social sphere in the regions of the Russian Federation

\begin{tabular}{|c|c|c|c|c|c|c|c|}
\hline & 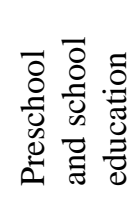 & 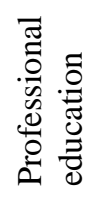 & 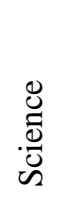 & 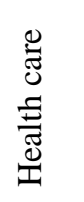 & 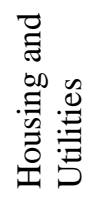 & 吾 & 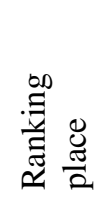 \\
\hline Republic of Bashkortostan & 0.59 & 0.77 & 0.27 & 0.58 & 0.77 & 2.98 & 3 \\
\hline Mari El Republic & 0.25 & 0.00 & 0.00 & 0.28 & 0.29 & 0.82 & 14 \\
\hline Republic of Mordovia & 0.32 & 0.04 & 0,03 & 0.48 & 0.20 & 1,07 & 13 \\
\hline Republic of Tatarstan & 0.73 & 0.97 & 0.45 & 0.28 & 0.75 & 3.18 & 2 \\
\hline Udmurtia & 0.33 & 0.25 & 0.09 & 0.56 & 0.08 & 1.3 & 12 \\
\hline Chuvash Republic & 0.47 & 0.10 & 0.08 & 0.54 & 0.25 & 1.43 & 10 \\
\hline Perm region & 0.36 & 0.46 & 0.29 & 0.67 & 0.27 & 2.05 & 6 \\
\hline Kirov region & 0.33 & 0.16 & 0,07 & 0.58 & 0.30 & 1.44 & 9 \\
\hline Nizhny Novgorod region & 0.63 & 0.56 & 0.92 & 0.74 & 0.59 & 3.44 & 1 \\
\hline Orenburg region & 0.41 & 0.26 & 0.09 & 0.58 & 0.36 & 1.7 & 7 \\
\hline Penza region & 0.24 & 0.08 & 0.10 & 0.40 & 0.49 & 1.31 & 11 \\
\hline Samara region & 0.32 & 0.66 & 0.28 & 0.53 & 0.73 & 2.52 & 4 \\
\hline Saratov region & 0.47 & 0.38 & 0.21 & 0.90 & 0.43 & 2,39 & 5 \\
\hline Ulyanovsk region & 0.27 & 0.14 & 0.17 & 0.41 & 0.53 & 1,52 & 8 \\
\hline
\end{tabular}

We can draw several conclusions based on the information given in the table.

Firstly, the integral assessments of the subjects of the Russian Federation differ significantly from each other. This indicates a significant difference between the regions in terms of the development of social infrastructure facilities. It is interesting to consider a similar scatter of the maximum and minimum estimates for each block. This indicator varies by industry. In the course of analysis, the following regularity of the scatter of estimates in different blocks was revealed. Two factors were identified that affect the difference in estimates: first, the mandatory provision of a public benefit, and secondly, the degree of competition and the development of the private sector in the social sphere. So, for example, in the Russian Federation, it is guaranteed accessibility and a free school and preschool education. The private sector is a little 
involved. In connection with this, the difference between the maximum and minimum ratings here is 0.48 points. On the contrary, vocational education is provided at the request of citizens on a competitive basis. In the vocational education market, there are many not only the state but also private organizations. Therefore, there is extremely strong competition in this area. In this regard, the spread of estimates is already 0.97 points.

The indicated pattern is also reflected in the position of regions in the ranking. High assessment of regions in such blocks as education, health care, housing and public utilities (in which services are provided necessarily, and competition in the market is low), does not allow them to form competitive advantages. In this regard, the position of these regions in the ranking is lower. This affects the general level of development of the region. Those entities that form an advantage in science or the field of vocational education have a higher position in the overall ranking. This is proved by the Nizhny Novgorod region, Tatarstan and Bashkortostan, which occupy the first three places in the ranking. The development level of these industries is high not only due to the formation of competitive advantages of the regions. Due to competition and private investment, these industries are developing more rapidly. This provides a more dynamic socioeconomic development of the regions.

The second group of conclusions concerns the state of different industries within each of the entities. To more clearly reflect these findings, a diagram was drawn up on the basis of the table (Figure 1). This diagram allows us to assess the range of estimates for each region.

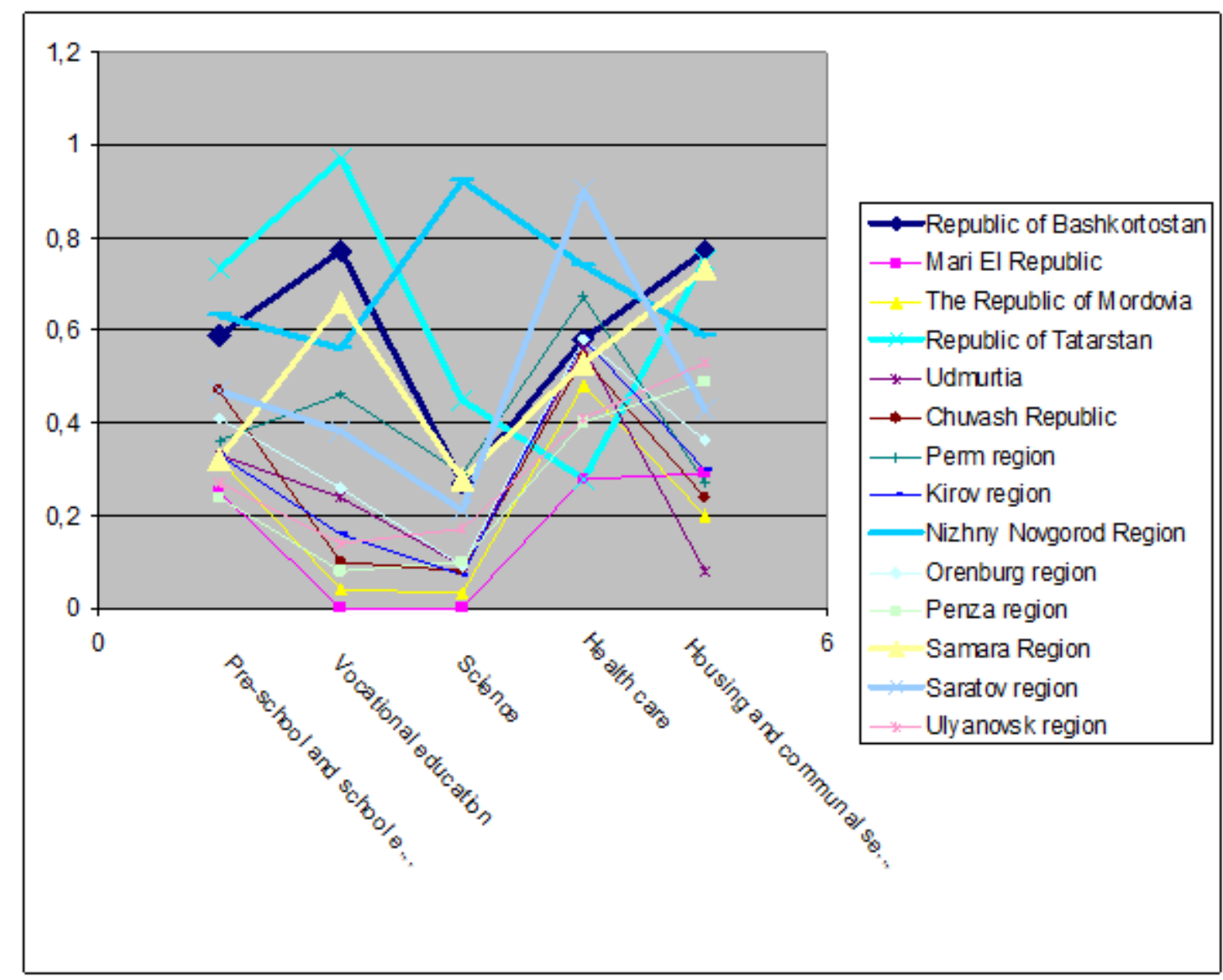

Fig. 1. The social sector development in the regions of the Russian Federation

The diagram shows that each region is characterized by a difference in estimates for different blocks. Information on the scatter in the estimates of each individual region is presented in table 2 . 
Table 2. The ratio of assessments for regions of the Russian Federation

\begin{tabular}{|c|c|c|c|c|}
\hline & $\begin{array}{l}\text { The place of } \\
\text { the region in } \\
\text { the ranking }\end{array}$ & $\begin{array}{l}\text { Maximum region } \\
\text { rating by the } \\
\text { block }\end{array}$ & $\begin{array}{l}\text { Minimum } \\
\text { assessment of the } \\
\text { region by the } \\
\text { block }\end{array}$ & $\begin{array}{l}\text { Scatter of the } \\
\text { maximum and } \\
\text { minimum } \\
\text { estimates of the } \\
\text { region }\end{array}$ \\
\hline Nizhny Novgorod region & 1 & 0.92 & 0.56 & 0.36 \\
\hline Republic of Tatarstan & 2 & 0.97 & 0.28 & 0.69 \\
\hline Republic of Bashkortostan & 3 & 0.77 & 0.27 & 0.5 \\
\hline Samara region & 4 & 0.73 & 0.28 & 0.45 \\
\hline Saratov region & 5 & 0.9 & 0.21 & 0,69 \\
\hline Perm region & 6 & 0.67 & 0.27 & 0.4 \\
\hline Orenburg region & 7 & 0.58 & 0.09 & 0.49 \\
\hline Ulyanovsk region & 8 & 0.56 & 0.17 & 0.39 \\
\hline Kirov region & 9 & 0.58 & 0,07 & 0.51 \\
\hline Chuvash Republic & 10 & 0.54 & 0.08 & 0.46 \\
\hline Penza region & 11 & 0.49 & 0.1 & 0.39 \\
\hline Udmurtia & 12 & 0.56 & 0.08 & 0.48 \\
\hline Republic of Mordovia & 13 & 0.48 & 0,03 & 0.45 \\
\hline Mari El Republic & 14 & 0.29 & 0 & 0.29 \\
\hline
\end{tabular}

Based on the scatter of estimates in each region, it is possible to classify the regions according to the level of development of social infrastructure.

So, it was found that the scatter of estimates in each of the groups is descending. That is, the region with the highest position in the group will have the largest spread, while for the rest it will gradually decrease. Thus, if the regions are assessed sequentially from the region with the highest rating to the region with the lowest rating, then the boundary between the groups of regions will be a jump in the difference between the highest and the lowest ratings. Table 2 shows that such jumps occur when assessing the Saratov region $\left(5^{\text {th }}\right.$ place in the rating) and Kirov region ( $9^{\text {th }}$ place in the rating). This allows us to select the following groups:

Regions with a high level of development of social infrastructure - places No. 1-4 in the ranking: Nizhny Novgorod and Samara regions, Tatarstan and Bashkortostan;

Regions with a satisfactory level of social infrastructure development - places No. 5-8 in the ranking: Saratov, Orenburg, Ulyanovsk regions and Perm Territory;

Regions with a low level of development of social infrastructure - places No. 9-14: Kirov and Penza regions, Mordovia, Chuvashia, Udmurtia, Mari El.

The first group includes regions that have formed their own competitive advantages. For example, Tatarstan is significantly ahead of other regions in terms of the development of vocational education, and Nizhny Novgorod region in terms of the development of science.

These advantages allow regions to maintain a high overall level of development of social infrastructure, despite failures in the development of some industries.

Regarding the second group of regions, the following can be noted. The level of their maximum rating is found at an average level of 0.5 , which makes it impossible to overcome competition with some regions and to rise higher in the rating.

The regions in the third group have no "points of growth", i.e., the strengths of the social infrastructure, so their maximum scores are below 0.5 on average. Because of this, the position of these regions in the ranking is lower than that of the others.

\section{Conclusions}


As a result of the analysis, it was found that the study of the social infrastructure should be carried out both in the sectoral and in the territorial aspects. A comparison of different branches of social infrastructure made it possible to identify some patterns that predetermine the degree of development. The study of individual territories (regions of the Russian Federation) made it possible to determine the level of development of social infrastructure in them, as well as to rank and classify them. Three groups of regions were identified. Each of the groups is characterized by certain trends in the development of the social sphere, which should be taken into account when conducting public policy.

Conclusions on the state of social infrastructure in the regions made it possible to identify some tools for its further development.

Thus, in the course of the analysis, it was found that the most dynamically developing sectors of the social sphere are those in which competition is developed thanks to the participation of private business. When assessing the development of such industries, regional indicators become more diverse. This increases the differentiation of regions and allows some of them to form a more developed social infrastructure. In this regard, measures are proposed that stimulate the development of the private sector in the social sphere. This can be facilitated by a tool such as public-private partnerships (PPPs). This mechanism will allow creating and maintaining social facilities. At the same time, the financial and administrative burden on the governing bodies of the region where the public-private partnership is highly developed will become less. This mechanism is relatively little used in the social sphere in the Russian Federation now, but abroad it has already shown its effectiveness.

The second group of tools is associated with the development of related industries. For example, in healthcare, private sector development can be facilitated by the development of a voluntary health insurance system. Buying a medical insurance policy will allow medical care to receive in private clinics. Due to this, the frequency of citizens' visits to non-state clinics can increase, as well as the interest of private business in investing in this industry. In the field of education, such an instrument can be educational loans or grant programs to support talented young people, and for science, it could obtain the form of venture funds and venture capital investments.

The third tool to increase the attractiveness of the social sphere for private investment is to increase incomes and solvency of the population. The demand for the services of commercial organizations in the social sphere depends on these indicators. The growth in demand for commercial services will stimulate the growth of supply in the social sectors.

The use of these tools should be coupled with the classification of regions. For regions with a high level of development, measures aimed at increasing the demand for private social services will be more priority. The level of development of social infrastructure in these regions is already quite high. In this regard, it is further advisable to increase the demand not only for free public services but also for better paid private services.

For regions with a satisfactory level of development of the social sphere, it is advisable to develop such tools as voluntary medical insurance, venture capital investments, grant support for youth, educational loans, etc. This will increase the demand for private services in the social sphere and make this segment of the social sphere more interesting for creating new private organizations.

For the third group of regions with low social development, active use of PPP is proposed, which will allow creating new social facilities without increasing the budget burden. This is extremely important for the regions of this group since their level of socio-economic development is lower than in other groups, that is, there is still little potential for the application of other proposed tools.

Thus, the tools and their application in individual constituent entities should contribute to the development of the social sphere in the regions of the Russian Federation. 


\section{Acknowledgements}

The work is performed according to the Russian Government Program of Competitive Growth of Kazan Federal University.

\section{REFERENCES}

1. Cui, Y., Sun, Y. The social benefit of urban infrastructure: An empirical analysis of 4 Chinese autonomous municipalities//Utilities Policy, Volume 58, June 2019, pp. 16-26.

2. Braveman, P., Gottlieb, L. The social determinants of health: It's time to consider the causes of the causes//Public Health Reports, Volume 129, Issue SUPPL. 2, 2014, pp. 19-31.

3. Kolbe, L.J. School Health as a Strategy to Improve Both Public Health and Education// Annual Review of Public Health, Volume 40, April 2019, pp. 443-463.

4. Zou, H., Luan, F., Xi, H., Yang, B. Comprehensive Management for Better Rural Infrastructure and Service Delivery: Lessons from the Implementation of China's Six Point Rural Action Plan in Guizhou Province//Advances in $21^{\text {st }}$ Century Human Settlements, 2020, pp. 279-300.

5. Bublitz, M.G., Peracchio, L.A., Dadzie, C.A., Escalas, J.E., Hansen, J., Hutton, M., Nardini, G., Absher, C., Tangari, A.H. Food access for all: Empowering innovative local infrastructure//Journal of Business Research, Volume 100, July 2019, pp. 354-365.

6. Opiyo, R.O., Muketha, S.M., Omollo, W.O., Mwaniki, D. Responsive infrastructure and service provision initiatives framing smart environment attainment in Nairobi//Advances in $21^{\text {st }}$ Century Human Settlements, 2020, pp. 407-433.

7. Herrero, Á., Jiménez, A. One-Class Classification to Predict the Success of Private-Participation infrastructure projects in Europe // Advances in Intelligent Systems and ComputingVolume 950, 2020, pp. 443-451.

8. Henisz, W.J. The institutional environment for infrastructure investment // Industrial and Corporate Change Volume 11, Issue 2, 2002, pp. 355-389.

9. Ramamurti, R., Doh, J.P. Rethinking foreign infrastructure investment in developing countries//Journal of World Business Volume 39, Issue 2, May 2004, pp. 151-167.

10. Hueskes, M., Verhoest, K., Block, T. Governing public-private partnerships for sustainability: An analysis of procurement and governance practices of PPP infrastructure projects// International Journal of Project Management Volume 35, Issue 6, August 2017, pp. 1184-1195.

11. Regions of Russia. Key socio-economic indicators. 2017. - Statistical Collection // Rosstat M., 2017. S. p. 1402.

\section{Article history:}

- Received 30 August 2019

- Accepted 14 November 2019 